\title{
Методологические и методические подходы к организации эксперимента в школьном курсе географии
}

\author{
Л.А. Межова ${ }^{1 凶}$, А.М. Луговской${ }^{2}$ \\ ${ }^{1}$ Воронежский государственный педагогический университет, Российская Федерация \\ (394043, г. Воронеж, ул. Ленина, 86) \\ ${ }^{2}$ Московский государственный университет геодезии и картографии, Российская Федераиия \\ (105064, г. Москва, Гороховский пер., 4)
}

\begin{abstract}
Аннотация: Цель: анализ возможности использования эксперимента при изучении школьного курса географии.

Maтериалы и методы: информационной базой служат отечественные и зарубежные исследования в области использования экспериментов в естественных науках. Применяемые методы - аналитический, моделирование, естественно-научный.

Результаты и обсуждение. В статье рассматриваются возможности использования эксперимента в школьном курсе географии. Дается понятие эксперимента с различных точек зрения и различных типов научных исследований. Использованы различные типы классификаций экспериментальной деятельности. Многовариантные эксперименты раскрывают широкие возможности для использования при изучении школьного курса географии. Построены структурные модели, позволяющие конструировать имитационный эксперимент на уроках географии.

Заключение. Экспериментальная деятельность обучающихся развивает их самостоятельность и познавательный интерес к изучению географии. Предлагаемый подход повысит эффективность учебного процесса в современной школе.
\end{abstract}

Ключевые слова: эксперимент, имитационный учебный эксперимент, исследовательский эксперимент, диагностический эксперимент, демонстрационный эксперимент, преобразующий эксперимент, констатирующий эксперимент, поисковой эксперимент, контролирующий эксперимент.

Для цитирования: Межова Л.А., Луговской А.М. Методологические и методические подходы к организации эксперимента в школьном курсе географии // Вестник Воронежского государственного университета. Серия: География. Геоэкология, 2021, № 4, с. 88-95. DOI: https://doi.org/10.17308/ geo.2021.4/3754

\section{ВВЕДЕНИЕ}

Объектом намего исследования является использование эксперимента в школьном курсе географии. Цель работы заключается в выявлении типологии и классификации экспериментов и возможностей их использования в процессе преподавания географических дисциплин в школе. Основные задачи: дать понятие эксперимента, изучить типологию и классификацию экспериментов, показать возможности имитационного эксперимента для повышения познавательной активности обучающихся, создать модель развития учебной деятельности средствами имитационного эксперимента.

\section{МАТЕРИАЛЫ И МЕТОДЫ}

Одной из основных проблем современной школы является повышение познавательной активности и интереса обучающихся. В последние годы значительное внимание уделяется организации самостоятельной деятельности обучающихся, которая помогает им получать новые знания и приобретать опыт.

В развитии теории и методики географии уделяется внимание использованию активных методов обучения. Перспективным является применение опытно-экспериментальной деятельности на уроках географии. В школьном курсе географии в

(C) Межова Л.А., Луговской А. М., 2021

Межова Лидия Александровна, e-mail: lidiya09mezhova@yandex.ru

Контент доступен под лицензией Creative Commons Attribution 4.0 License. 
настоящее время эксперимент практически не используется, но он может быть крайне эффективен в процессе изучения дисциплины. Эксперимент позволит изменить характер учебной деятельности школьников и перейти от репродуктивной к продуктивной деятельности, направленной на получение субъективно новых знаний.

По исследованиям К. П. Ягодовского, А. Я. Герда, М.Н. Скаткина, Б. Е. Райкова доказано, что методы наблюдения, опыт и эксперимент эффективны при получении знаний о природных объектах и явлениях, которые объясняют взаимосвязи, закономерности в природе и активизируют познавательную деятельность $[5,8]$.

Техника и методика учебного эксперимента разработана в трудах А. В. Перыщкина, А.И. Бугаева, В. Г. Разумовского, Л. И. Анциферова, П.И. Знаменского, С.Е. Каменецкого, Ю.И. Дика [3, 9, 10]. По их мнению учебный эксперимент - это система программных и технических методов, позволяющих получить субъективно новые знания об изучении предметов и явлений на основе использования различных подходов.

\section{РЕЗУЛЬТАТЫ И ОБСУЖДЕНИЕ}

Для оптимизации учебной деятельности в школьном курсе географии необходимо определить основные подходы к развитию учебной деятельности средствами экспериментальной работы. Использование системного подхода развивает самостоятельную деятельность, экспериментальная работа помогает изучать отношения и связи. Личностно-деятельностный подход рассматривает личность как субъект и как результат деятельности в процессе общения. Понятие «эксперимент» представляет набор эмпирических действий, направленных на проверку основных предположений в стандартных воспроизводимых условиях, математическую и статистическую обработку.

«Учебный эксперимент» - это система методов, средств, целей использования для получения субъективно новых знаний об объектах и явлениях с целью воспроизведения явлений в искусственных условиях, создания новых объектов, измерения, сопоставления, фиксирования экспериментальных данных средствами специально разработанных технических средств [1].

«Имитационный учебный эксперимент» это проводимый самостоятельно по алгоритму порядок действий для создания образа формируемого элемента знаний: представления, конкретного понятия, метапредметного понятия и компетенции. В наибольшей степени экспери- мент проводится при изучении физической географии.

Под экспериментом понимают метод, на основе которого в контролируемых условиях осуществляется познание предметов и явлений действительности, затем формулируются и проверяются гипотезы, которые активизируют научное познание мира. На основе экспериментального метода воспроизводятся объекты и явления в специально созданных условиях [4]. Эксперимент позволяет многократно воспроизводить исследуемые процессы исследователем для верификации гипотезы исследования и выявлять свойства явлений и объектов [6].

Эксперименты разделяют по характеру предмета и делят на эстетические, педагогические, правовые, социологические, социально-психологические, психологические, экономические, географические и экологические. По структуре их разделяют на простые и сложные. Простые эксперименты проводят для изучения объектов с простой структурой, а сложные включают большое количество связанных элементов.

По характеру объекта эксперимент делят на мысленный и реальный. При проведении реального эксперимента исследователь работает с реальным объектом, используя планомерные изменения условий. Мысленный эксперимент также называют идеализированным, так как используется мысленная модель объекта, на основе которой формируется структура реального эксперимента. В эксперимент включены процессы наблюдения и сам эксперимент.

Среди классификаций эксперимента выделяют классификацию В.В. Никандрова, в которой обобщены и выявлены основные разновидности эксперимента. В основу положена действительность проведения и полнота процедуры: реальные (конкретные) и мыслительные (абстрактные). Мыслительные подразделяют на три подгруппы: идеальный, бесконечный, безупречный. По Д. Кэмпбеллу эксперимент различается по цели: исследовательский, диагностический, демонстрационный, которые основаны на положениях Л.С. Выготского. Уровни исследования в экспериментах, по А. П. Куприянову, делят на предварительный (разведывательный), основной, контрольный [12].

По типу воздействия выделяют внутренний и внешний, а по типу экспериментальной ситуации - лабораторный, естественный и формирующий. По количеству переменных эксперименты делятся на одно- и многофакторные. В психологии, соци- 
ологии и педагогике, по Б.Ф. Скиннеру и Р. Готтсданкеру, эксперименты проводятся с людьми, поэтому выделяют индивидуальные и групповые [11].

Типология эксперимента заключается и в природе изучаемых объектов. Выделяют технологические, социометрические, физические, экономические. Технологический направлен на изучение технологического процесса в целом и его отдельных элементов. Экономический схож с технологическим, но касается в основном персонала, социо- метрический эксперимент проводят для исследования межличностных отношений в малых группах для их изменения. В зависимости от поставленных целей и задачи типов эксперимента их объединяют, тогда образуются комплексные эксперименты [2].

В зависимости от цели эксперимента выделяют 5 категорий: преобразующие, констатирующие, контролирующие, поисковые, решающие. Особенности каждого эксперимента представлены на рисунке 1.

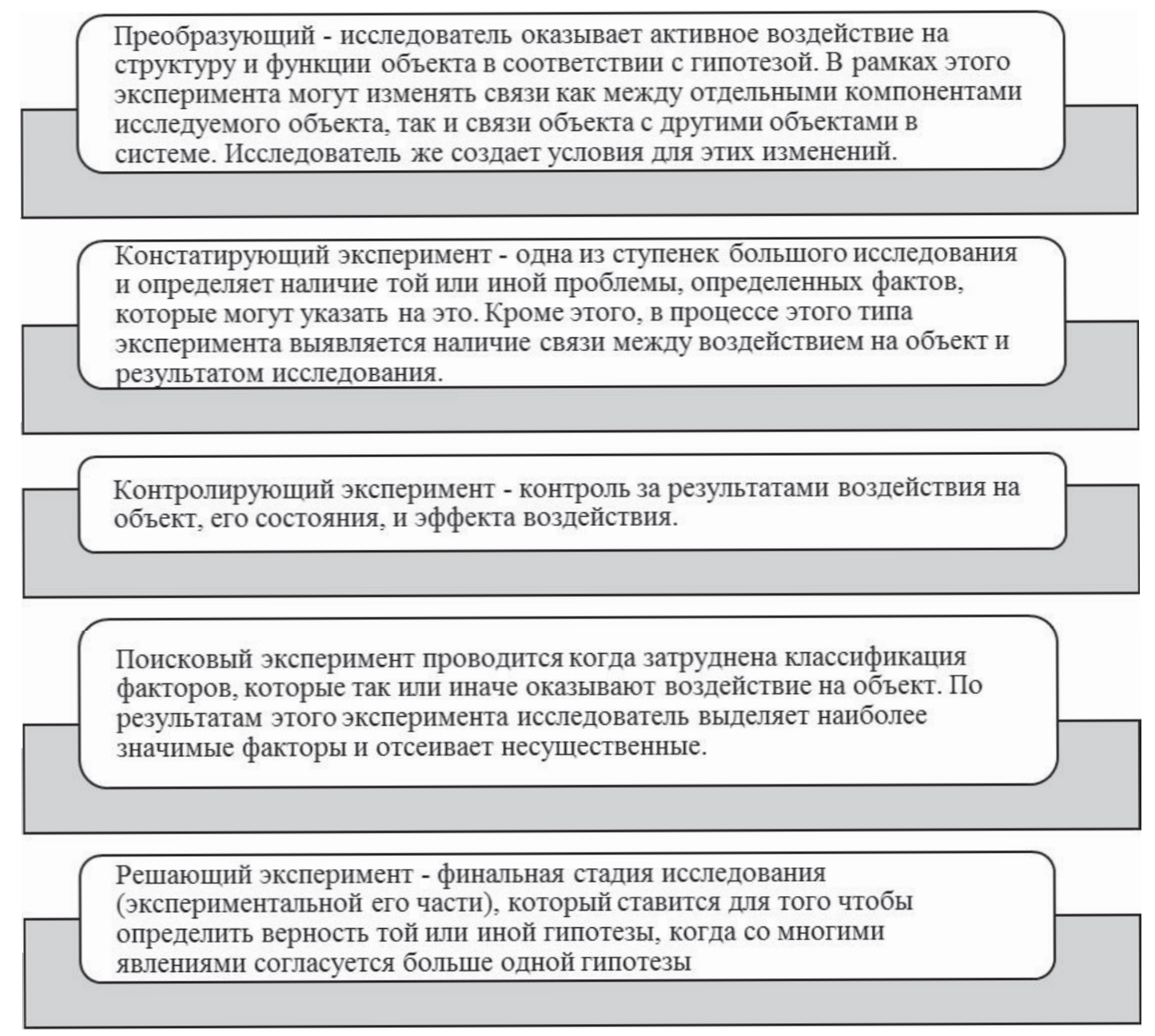

Puc. 1. Особенности категорий эксперимента по целям

[Fig. 1. Peculiarities of the categories of experiment by purposes]

Полевой эксперимент проводят в естественных условиях. Компьютерные модельные эксперименты строятся на системном преобразовании информации. Такой эксперимент решает задачи анализа и синтеза большого количества информации при помощи идеальных компьютерных моделей. Преобладающими являются вычислительные и компьютерные имитационные эксперименты. Эксперименты различаются по факторам, воздействию и результатам. Основные классификационные признаки представлены на рисунке 2.
Мыслительный эксперимент строится на применении законов науки на всех стадиях эксперимента. При проведении материального эксперимента формируются мысленные, а реальные объекты, кроме того, в материальном эксперименте есть материальная связь сознания с внешним миром.

При этом мысленный эксперимент в большинстве случаев предваряет реальный и является идеализированной версией, и чаще всего применяется, когда реальный воспроизвести невозможно. 


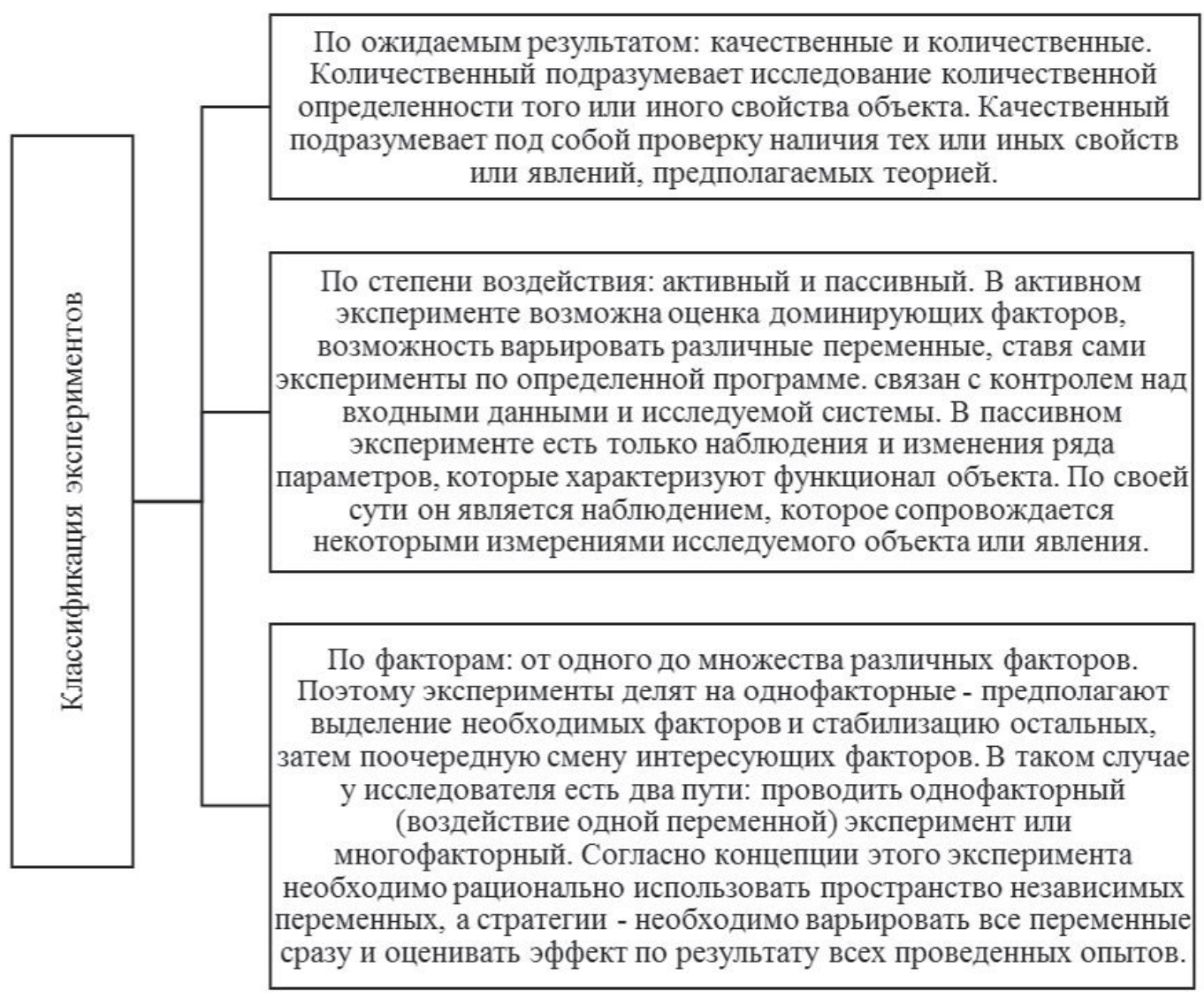

Puc. 2. Основные классификационные признаки эксперимента

[Fig. 2. The main classification attributes of the experiment]

Перед проведением эксперимента определяют круг задач и цель, направление: научное и прикладное. Эксперименты могут быть проективными и ретроспективными.

По характеру управления экспоненты делят на контролируемые и неконтролируемые. На результаты оказывает влияние посторонние факторы, и степень их влияния остается неизвестна на протяжении всего эксперимента.

Лабораторный эксперимент считают вариантом контролируемого, причем он заключается в создании условий, в котором его максимально приближают к реальным. Лабораторный эксперимент основан на создании ситуаций, в которых контролируется переменные и определяется процесс изменения [9].

По организационным условиям выделяют: лабораторные, полевые, натурные, производственные эксперименты. Производственный характеризуется сбором материалов в различных организациях. По месту проведения эксперимента выделяют: полевые, натурные, полунатурные, полигонные, производственные, демонстрационные

В эксперименте взаимодействуют как средства исследования, так и объекты и их можно разделить на обычные и модельные. Эксперимент может быть пассивным и активным и отличается контролируемыми величинами.

По функциям выделяют 3 типа эксперимента: разведочный, основной, контрольный, при этом разведочный проводится для уточнения задач основного, а контрольный используется при дополнительной проверке результатов. Экстремальный эксперимент делится на отсеивающий, описательный, сравнительный [7].

Наиболее перспективным в курсе географии является проведение имитационного эксперимента (рис. 3).

Такой эксперимент позволяет преобразовать знания в совершенно новый субъективный опыт деятельности и конструировать способы деятельности для решения проблем, получить новые знания в различных ситуациях. Знания методики экспериментальной деятельности позволяют развивать личность в совершенствовании рефлективности и целеполагания, самодисциплины и самосознания. На уроках географии эффективны средства имитационного моделирования (рис. 4.).

Целью реализации модели является развитие учебной деятельности при непосредственном исследовании объектов средствами эксперимен- 
та и переход от репродуктивного к исследовательскому типу деятельности. В этой системе самостоятельный элемент (преподаватель и обучающийся) находится во втором контуре, а сама информация - в первом. Имитационная система средств обучения на пересечении контуров включает имитационный эксперимент с тесной взаимосвязью компонентов, подчиненных единой цели.
Организация учебной деятельности средствами имитационного эксперимента позволяет организовать процесс получения обучающимися личностно новых знаний и практических навыков, основанных на практической работе при трансформации репродуктивного уровня в частично-поисковый и поисково-проблемный уровень творческой деятельности в процессе формирования метакомпетенций в курсе географии.

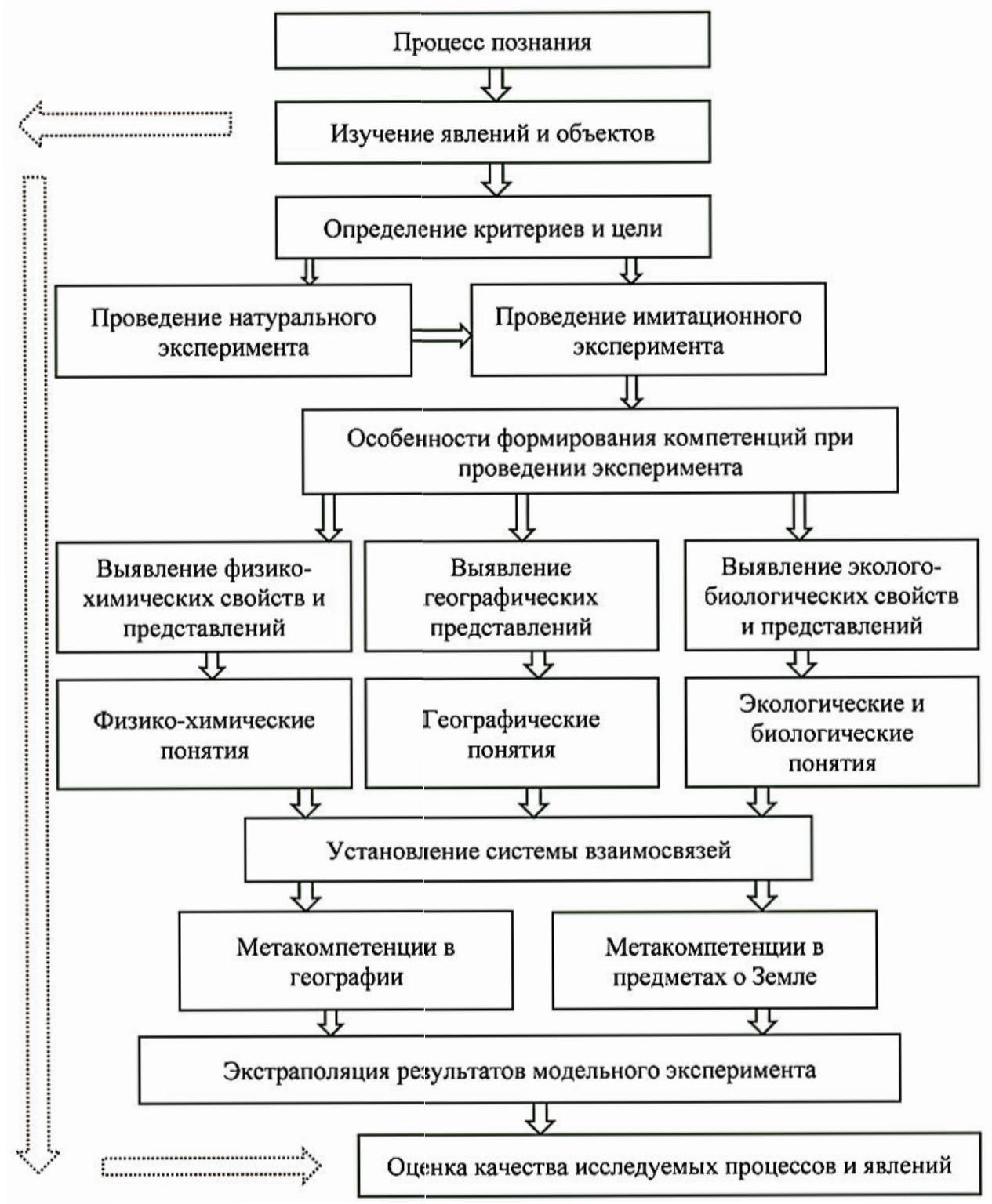

Puc. 3. Система организации имитационного эксперимента в школьном курсе географии

[Fig. 3. The system for organizing a simulation experiment in a school geography course]

Методика развития учебной деятельности средствами имитационного эксперимента объединяет объективные (информация, учитель, школьник, система средств обучения) и субъективные компоненты (цель, содержание, поисковой алгоритм, методы реализации и формы организации обучения) на основе их взаимодействия.

Использование имитационного эксперимента предполагает выбор обучающимися методов формирования комплекса специфических компетенций и метакомпетенций учебной деятельности 
в курсе географии с учетом субординационных и координационных связей предметов естественнонаучного и гуманитарного циклов путем выбора технологических средств учебного имитационного эксперимента; сочетание аудиторной и внеклассной форм учебной деятельности и реализации системы имитационного эксперимента при выполнении практических работ в структу- ре учебного процесса школьников в курсе географии. Выполняется система самостоятельных практических заданий, позволяющих развивать активные качества личности школьника и применение системы контрольных измерителей и параметров оценки личностного развития обучающихся при выполнении учебного имитационного эксперимента.

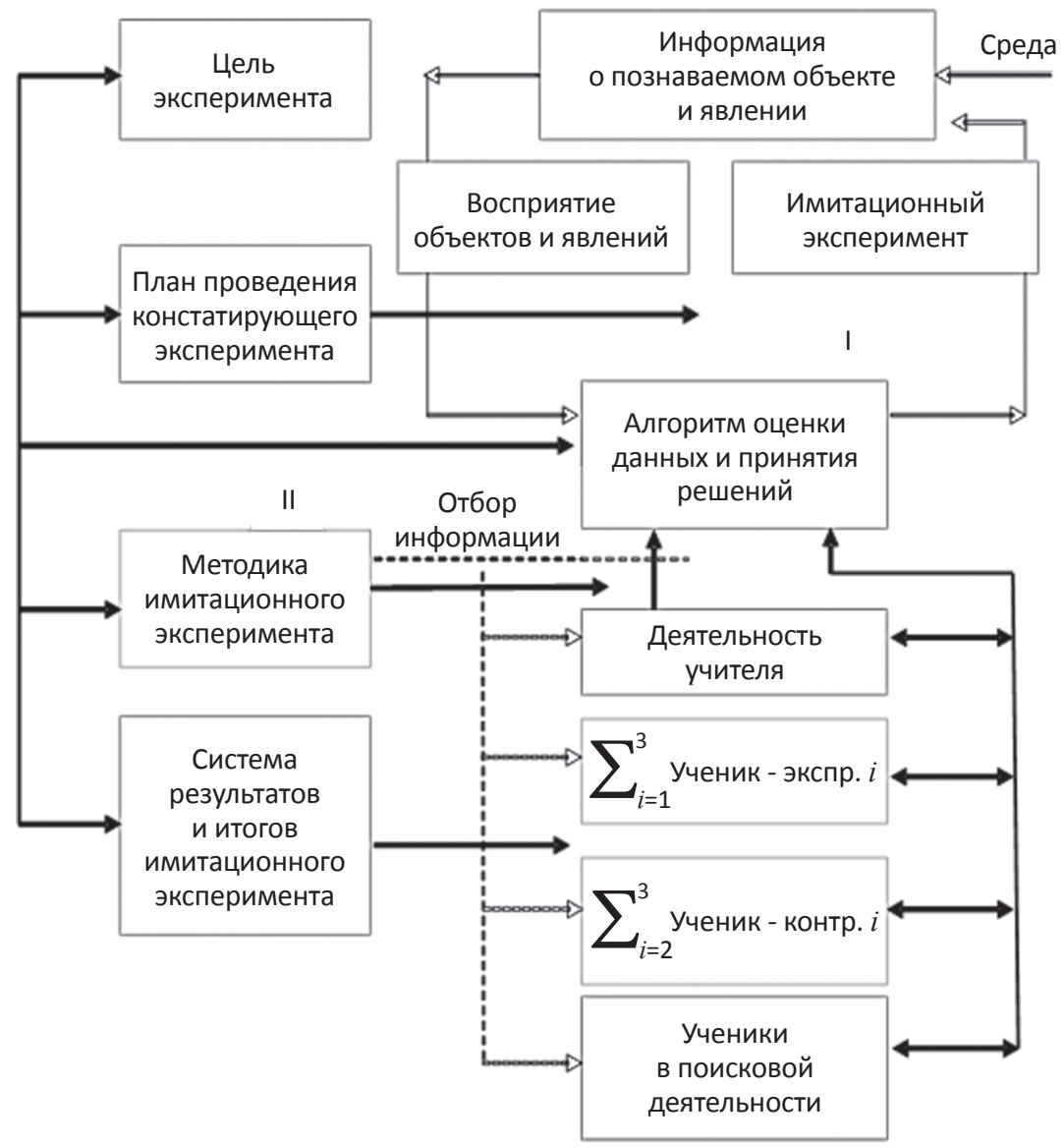

Puc. 4. Модель развития учебной деятельности обучающихся средствами имитационного эксперимента:

I - Восприятие объекта, явления, процесса; II - учебная деятельность обучающихся при проведении имитационного эксперимента

[Fig. 4. Model for the development of students' learning activities by means of a simulation experiment:

I - Perception of an object, phenomenon, process; II - Learning activities of students in a simulation experiment]

\section{ЗАКЛЮЧЕНИЕ}

Таким образом, экспериментальная деятельность способствует приобретению обучающимися субъективно новых знаний, опыта деятельности их применения в переходе к продуктивной деятельности от репродуктивной. Эксперимент позволяет провести оптимизацию учебного процесса, повысить качество и эффективность, а также улучшить качество подготовки обучающихся. Эксперимент способствует активизации и познавательной деятельности школьников, формированию опыта исследовательской де- ятельности, рефлексивных умений, самостоятельной, творческой активности, саморазвитию. Совершенствуется урочная и внеурочная самостоятельная деятельность обучающихся при изучении географии.

\section{СПИСОК ЛИТЕРАТУРЫ}

1. Буянов А. О., Луговской А. М. Методика учебной деятельности на уроках географии средствами демонстрационного эксперимента // Проблемы региональной экологии, 2014, № 3, с. 146-149.

2. Буянов А.О., Луговской А.М. Эффективность формирования представлений в процессе опытно-экс- 
периментальной работы на уроках географии // Maтериаль международной научно-практической конференции «Экологические, экономические и социально-культурные предпосылки трансграничного сотрудничества в Балтийском регионе», 2012, с. 244-249.

3. Гайсумова Л. Д., Чатаева М.Ж. Наглядность как метод формирования понятий, явлений и образов на уроках географии // Образование и воспитание, 2016, №3 (8), с. 19-22.

4. Дронов В. П., Лобжанидзе А. А., Лопатников Д. Л. Концептуальные подходы к изучению географии в старшей школе // Наука и школа, 2018, № 3, с. 9-16

5. Заграничная Н.А., Паршутина Л.А., Пентин А.Ю. Научный метод познания в школьном естественнонаучном образовании: обучение химии и биологии // Отечественная и зарубежная педагогика, 2019, № 1 (57), с. 6-27

6. Задорожнюк В.Э., Задорожнюк Г.Н. Эксперименты на уроках географии // Материаль ІІІ Международного профессионально-методического конкурса «Педагогическое призвание», 2021, с.183-191

7. Луговской А.М., Буянов А.О. Место и роль учебного демонстрационного эксперимента в курсе физической географии в процессе формирования компетенций // Современные проблемы науки и образования, 2014, № 2, с. 262.
8. Межова Л.А., Буянов А.О., Сагова 3. М. Принципы и методика организации учебной экспериментальной деятельности на уроках географии // Материальг X Всероссийской научно-практической конференции с международным участием «Территориальная организация общества и управление в регионах», 2015, c. 191-196.

9. Разумовский В.Г., Майер В.В. Физика в иколе. Научный метод познания и обучение. Москва: Владос, 2004. $463 \mathrm{c}$.

10. Разумовский В. Г. Развитие творческих способностей учашихся в процессе обучения физике: пособие для учителей. Москва: Просвещение, 1975. 272 с.

11. Скиннер Б. Ф. Наука и человеческое поведение. Пер. с англ. А.А. Федорова, А. И. Васильева. Новосибирск, 2017. 517 с.

12. Хуторской А.В. Компетентностный подход в обучении: Научно-методическое пособие. Москва: Издательство «Эйдос»; Издательство Института образования человека, 2013. 73 с.

Конфликт интересов: Авторы декларируют отсутствие явных и потенциальных конфликтов интересов, связанных с публикацией настоящей статьи

Поступила в редакциию 12.10.2021 Принята к публикации 23.11.2021

\title{
Methodological and Methodical Approaches to Organizing an Experiment in a School Geography Course
}

\author{
L.A. Mezhova ${ }^{1 凶}$, A. M. Lugovskoy ${ }^{2}$ \\ ${ }^{1}$ Voronezh State Pedagogical University, Russian Federation \\ (394043, Voronezh, Lenin Str., 86) \\ ${ }^{2}$ Moscow State University of Geodesy and Cartography, Russian Federation \\ (105064, Moscow, Gorokhovsky per., 4)
}

\begin{abstract}
The purpose of the study is to analyze the possibility of using an experiment in a school geography course.

Materials and methods: The information base is domestic and foreign research on the use of experiments in the natural sciences. Analytical, modelling and natural science methods were used in the study.

Results and discussion. This article discusses the use of experimentation in a school geography course. The concept of experiment from different perspectives and different types of scientific research is given. Different types of classifications of experimental activities are used. Multivariate experiments reveal a wide range of possibilities for use in the study of school geography course. The structural models have been developed that enable simulation experiments to be carried out in geography lessons.
\end{abstract}

(C) Mezhova L.A., Lugovskoy A. M., 2021

\.ydia A. Mezhova, e-mail: lidiya09mezhova@yandex.ru

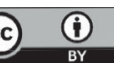

94

The content is available under Creative Commons Attribution 4.0 License. 


\section{Methodological and Methodical Approaches to Organizing an Experiment in a School Geography Course}

Conclusion. Experimental activities develop students' independence and cognitive interest in learning geography. The proposed approach will increase the effectiveness of the learning process in a modern school.

Key words: experiment, simulation learning experiment, research experiment, diagnostic experiment, demonstration experiment, transformative experiment, statement experiment, search experiment, control experiment.

For citation: Mezhova L.A., Lugovskoy A. M. Methodological and Methodical Approaches to Organizing an Experiment in a School Geography Course. Vestnik Voronezskogo gosudarstvennogo universiteta. Seria: Geografia. Geoekologia, 2021, no. 4, pp. 88-95. (In Russ.). DOI: https://doi.org/10.17308/geo.2021.4/3754

\section{REFERENCES}

1. Buyanov A. O., Lugovskoj A. M. Metodika uchebnoj deyatel'nosti na urokah geografii sredstvami demonstracionnogo eksperimenta [Methods of learning activities in geography classes by means of a demonstration experiment]. Problems of regional ecology, 2014, no. 3, pp. 146149. (in Russ)

2. Buyanov A.O., Lugovskoj A.M. Effektivnost' formirovaniya predstavlenij $\mathrm{V}$ processe opytno-eksperimental'noj raboty na urokah geografii [The effectiveness of the formation of ideas in the process of experimental work in geography classes]. Materials of the International Scientific and Practical Conference «Ecological, economic and socio-cultural prerequisites for transboundary cooperation in the Baltic region», 2012, pp. 244-249. (in Russ)

3. Gajsumova L.D., CHataeva M.Zh. Naglyadnost' kak metod formirovaniya ponyatij, yavlenij i obrazov na urokah geografii [Visualization as a method of forming concepts, phenomena and images in geography classes]. Education and upbringing, 2016, no. 3 (8), c. 19-22. (in Russ)

4. Dronov V.P., Lobzhanidze A.A., Lopatnikov D.L. Konceptual'nye podhody $\mathrm{k}$ izucheniyu geografii $\mathrm{v}$ starshej shkole [Conceptual approaches to the study of geography in high school]. Science and School, 2018, no. 3, pp. 9-16 (in Russ)

5. Zagranichnaya N.A., Parshutina L.A., Pentin A.Yu. Nauchnyj metod poznaniya $\mathrm{v}$ shkol'nom estestvennonauchnom obrazovanii: obuchenie himii i biologii [The Scientific Method of Knowledge in School Science Education: Teaching Chemistry and Biology]. Domestic and foreign pedagogy, 2019, no. 1 (57), c. 6-27 (in Russ)

6. Zadorozhnyuk V.E., Zadorozhnyuk G. N. Eksperimenty na urokah geografii [Experiments in Geography Classes]. Materialy III Mezhdunarodnogo professional'no-metodicheskogo konkursa «Pedagogicheskoe prizvanie», 2021, pp. 183-191. (in Russ)

\section{Межова Лидия Александровна}

кандидат географических наук, доцент кафедры географии и туризма Воронежского государственного педагогического университета, г. Воронеж, Российская Федерация, ORCID: 0000-0002-6652-5120, e-mail: lidiya09mezhova@yandex.ru

Луговской Александр Михайлович

доктор географических наук, профессор кафедры географии ФГБОУ ВО «Московский государственный университет геодезии и картографии», г. Москва, Российская Федерация, ORCID: 0000-0002-3985-4535, e-mail: alug1961@yandex.ru
7. Lugovskoj A. M., Buyanov A. O. Mesto i rol' uchebnogo demonstracionnogo eksperimenta $\mathrm{v}$ kurse fizicheskoj geografii $\mathrm{v}$ processe formirovaniya kompetencij [Place and role of educational demonstration experiment in the course of physical geography in the formation of competencies]. Modern problems of science and education, 2014, no. 2, p. 262. (in Russ)

8. Mezhova L.A., Buyanov A.O., Sagova Z.M. Principy $i$ metodika organizacii uchebnoj eksperimental'noj deyatel'nosti na urokah geografii [Principles and Methodology of the Organization of Educational Experimental Activity at Geography Lessons]. Materialy X Vserossiyskoy nauchno-prakticheskoy konferentsii s mezhdunarodnym uchastiem «Territorial'naya organizatsiya obshchestva i upravlenie v regionakh», 2015, p. 191-196. (in Russ)

9. Razumovskij V.G., Majer V.V. Fizika v shkole. Nauchnyj metod poznaniya i obuchenie [Physics at School]. Moscow: Vlados, 2004. 463 p. (in Russ)

10. Razumovskij V. G. Razvitie tvorcheskih sposobnostej uchashchihsya v processe obucheniya fizike: posobie dlya uchitelej [The Development of Creative Abilities of Students in the Teaching of Physics: A Manual for Teachers]. Moscow: Prosveshcheniye, 1975. 272 p. (in Russ)

11. Skinner B.F. Nauka i chelovecheskoe povedenie [Science and Human Behavior]. Translated from English by A.A. Fedorov, A.I. Vasiliev. Novosibirsk, 2017. 517 p. (in Russ)

12. Hutorskoj A.V. Kompetentnostnyj podhod v obuchenii: Nauchno-metodicheskoe posobie [Competency-Based Approach in Teaching: Scientific and Methodical Manual]. Moscow: Publishing house "Eidos"; Publishing house of the Institute of Human Education, 2013. 73 p. (in Russ)

Conflict of interest: The authors declare no information of obvious and potential conflicts of interest related to the publication of this article.

Received: 12.10 .2021

Accepted: 23.11.2021

Lydia A. Mezhova

Cand. (Geogr.) Sci., Associate Professor of the Department of Geography and Tourism, Voronezh State Pedagogical University, Voronezh, Russian Federation, ORCID: 00000002-6652-5120, e-mail: lidiya09mezhova@yandex.ru

Alexander M. Lugovskoy

Doctor of Geographical Sciences, Professor of the Department of Geography, Moscow State University of Geodesy and Cartography, Moscow, Russian Federation, ORCID: 0000-0002-3985-4535, e-mail: alug1961@yandex.ru 